УДК 663.14. 033, 663.143.2

Ободович А.Н., Сидоренко В.В.

Институт технической теплофизики НАН Украины, г. Киев

\title{
БАРДА СПИРТОВЫХ ЗАВОДОВ - ЦЕННЫЙ ОТХОД ДЛЯ ПРОИЗВОДСТВА КОРМОВЫХ ДРОЖЖЕЙ И БЕТОНА
}

В статье представлен обзор свойств и назначение послеспиртовой барды как иенного сырья в биотехнологии (питательная среда в производстве кормовых дрожжей), так и в строительстве (активная добавка в бетон).

У статті представлений огляд властивостей і призначення післяспиртової барди як цінної сировини в біотехнологї (поживна середу у виробниџтві кормових дріжджів), так $і$ в будівництві (активна добавка в бетон).

The article provides an overview of the properties and purpose of distillery slops of distilleries as a valuable raw material in biotechnology (growth medium in the production of fodder yeast) and in construction (active additive in concrete).

В производстве бетона применяют различные химические добавки, повышающие его пластичность и прочность. В качестве активной добавки к бетону возможно применять последрожжевую барду, оказывающую на бетонную смесь разжижающее и пластифицирующее действие [1].

Последрожжевая барда является отходом производства кормовых дрожжей. Основным сырьём для производства кормовых дрожжей является послеспиртовая барда (отход спиртового производства) с добавлением необходимых питательных веществ, содержащих азот, фосфор и т.д.

Барда с добавлением этих питательных веществ является полноценной средой для выращивания кормовых дрожжей. Зерновая барда содержит $7-8$ \% сухих веществ. Состав сухих веществ (\%): сахаров $0,2-0,45$; глицерина $0,4-0,6$; крахмала $0,1-0,2$; гемицеллюлоз 1,4 - 2,3; целлюлозы 0,3 - 0,9, также присутствуют белки, аминокислоты, органические кислоты и минеральные соединения [2]. Кроме того, барда содержит больше питательных веществ при наличии в ней автолизата спиртовых дрожжей. 
Кормовые дрожжи представляют собой смесь дрожжей Saccharomyces cerevisiae и дрожжеподобных грибов Candida. Кормовые дрожжи выращивают в ферментационных аппаратах при температуре $30-35{ }^{\circ} \mathrm{C}$ в течение 12 - 20 часов. На скорость роста и качество как кормовых дрожжей влияет состав питательной среды, температура, $\mathrm{pH}$, насыщение среды кислородом. Именно степень аэрации является главным лимитирующим фактором при получении дрожжевой биомассы.

В качестве устройства по интесификации процесса растворения кислорода в культуральных жидкостях (в том числе и послеспиртовой барде) при культивировании микроорганизмов была создана ферментационная установка с дискретно-импульсным вводом энергии, основным рабочим органом которого является роторно - пульсационный аппарат, аппаратурно - технологическая схема которой представлена на рис. 1.

Суть метода заключается в том, что энергия, вводимая в аппарат для интенсификации тепломассообменных процессов, распределяется дискретно во времени и по объему дисперсной системы в рабочей зоне аппарата в виде коротких мощных импульсов [3]. Процесс переноса вещества на границе раздела фаз происходит вследствие двух диффузионных составляющих: молекулярной и турбулентной, объединённых коэффициентом эффективной диффузии. При этом влияние турбулентной диффузии может значительно превышать молекулярную, определяя интенсивность процесса. Таким образом, скорость массообмена в системе газ - жидкость в общем виде зависит как от физикохимических свойств газа и жидкости, площади поверхности контакта фаз, так от гидродинамической обстановки вокруг границы раздела фаз.

Обработка культуральных сред в ферментёрах с применением метода дискретно импульсного ввода энергии позволяет решить комплекс задач: высокочастотные пульсации среды и развитая турбулентность в рабочей зоне аппарата способствуют как диспергированию пузырьков подаваемого на аэрацию воздуха, увеличивая поверхность контакта фаз, так и увеличению турбулентной составляющей эффективной диффузии. Кроме того, такая обработка способствует равномерному распределению клеток по всему объёму культуральной жидкости. 


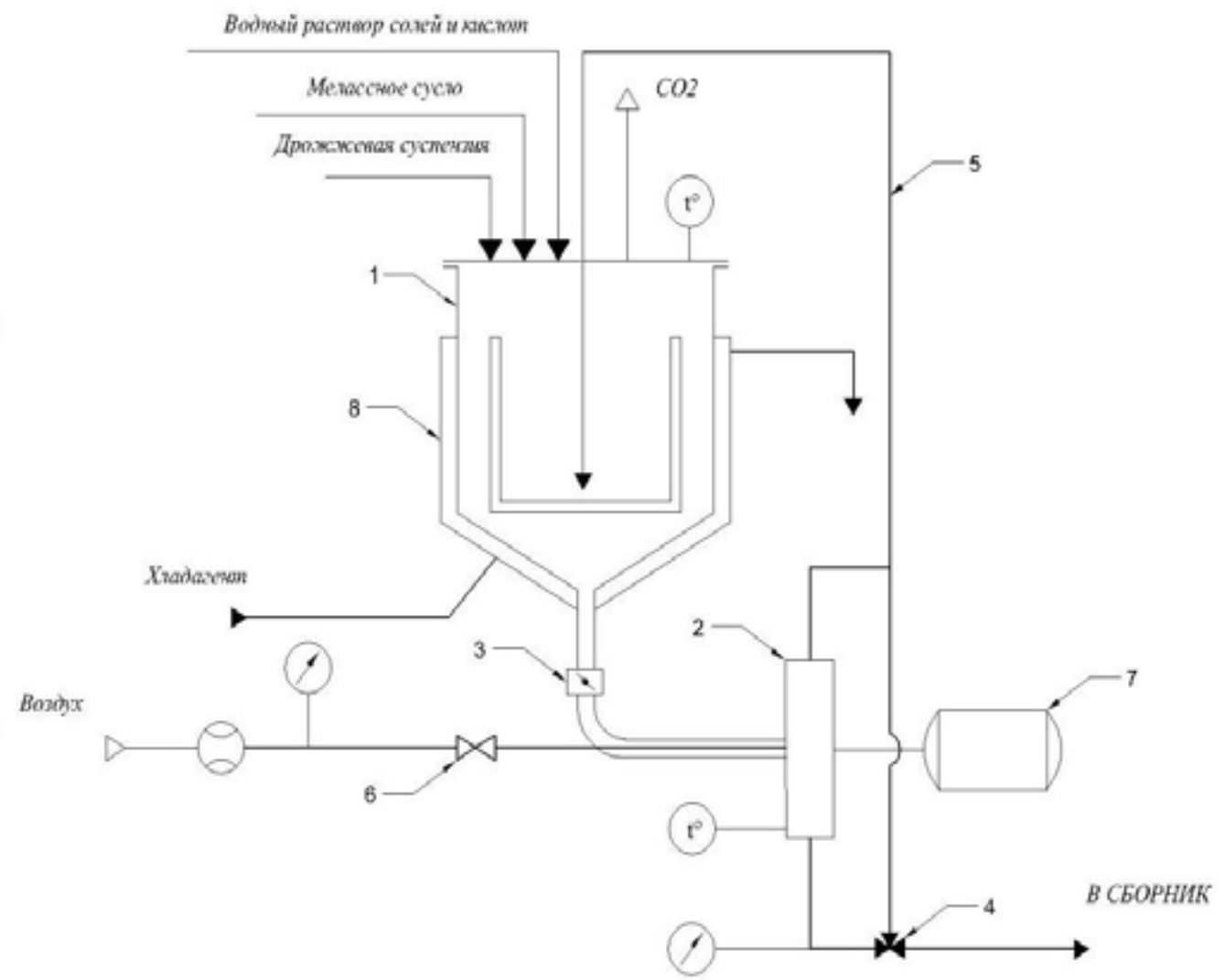

Рис. 1 - Аппаратурно - технологическая схема ферментационной установки с дискретно - импульсным вводом энергии:

1 - бункер; 2 - роторно - пульсационный аппарат; 3 - заслонка; 4 - трёхходовой кран; 5 - трубопровод рециркуляции; 6 - двухходовой кран; 7 - двигатель; 8 -рубашка охлаждения.

Выбирая оптимальне параметры дискретно - импульсного ввода энергии, можно интенсифицировать технологию кормовых дрожжей (снизить продолжительность процесса, повысить выход готовой продукции, улучшить её качество).

Отходом производства кормовых дрожжей является последрожжевая барда, которая является вредным стоком спиртового и дрожжевого производства. Проблема обезвреживания и использования этих стоков является самой актуальной и сложной для спиртовых и дрожжевых заводов. 
В работе предложено использовать последрожжевую барду, сгущенную до $70-75 \%$ CB в качестве добавки в бетонную смесь, оказывающую разжижающее и пластифицирующее действие.

Оптимальную добавку последрожжевой барды устанавливали в условиях естественного и тепловлажного твердения на бетонных смесях и затвердевших бетонах марки 800, на цементе активностью 58,3 МПа. На 1 м³ бетона расходовали цемента 562 кг, песка речного 400 кг, щебня 1450 кг, воды 145 - 170 л, что соответствовало водо-цементному отношению 0,26 и 0,30. Наиболее отчетливо уменьшалось водо-цементное соотношение (В/Ц) при содержании в смеси $0,15 \%$ последрожжевой барды от массы цемента (по СВ) и с увеличением ее количества не изменялось. Добавка последрожжевой барды в количестве 0,1 - 0,2\% (по сухим веществам) к массе цемента обеспечивала наибольшую прочность бетона.

О влиянии последрожжевой барды на прочность бетонов, полученных на цементе активностью 50 МПа, можно судить по рис. 2.

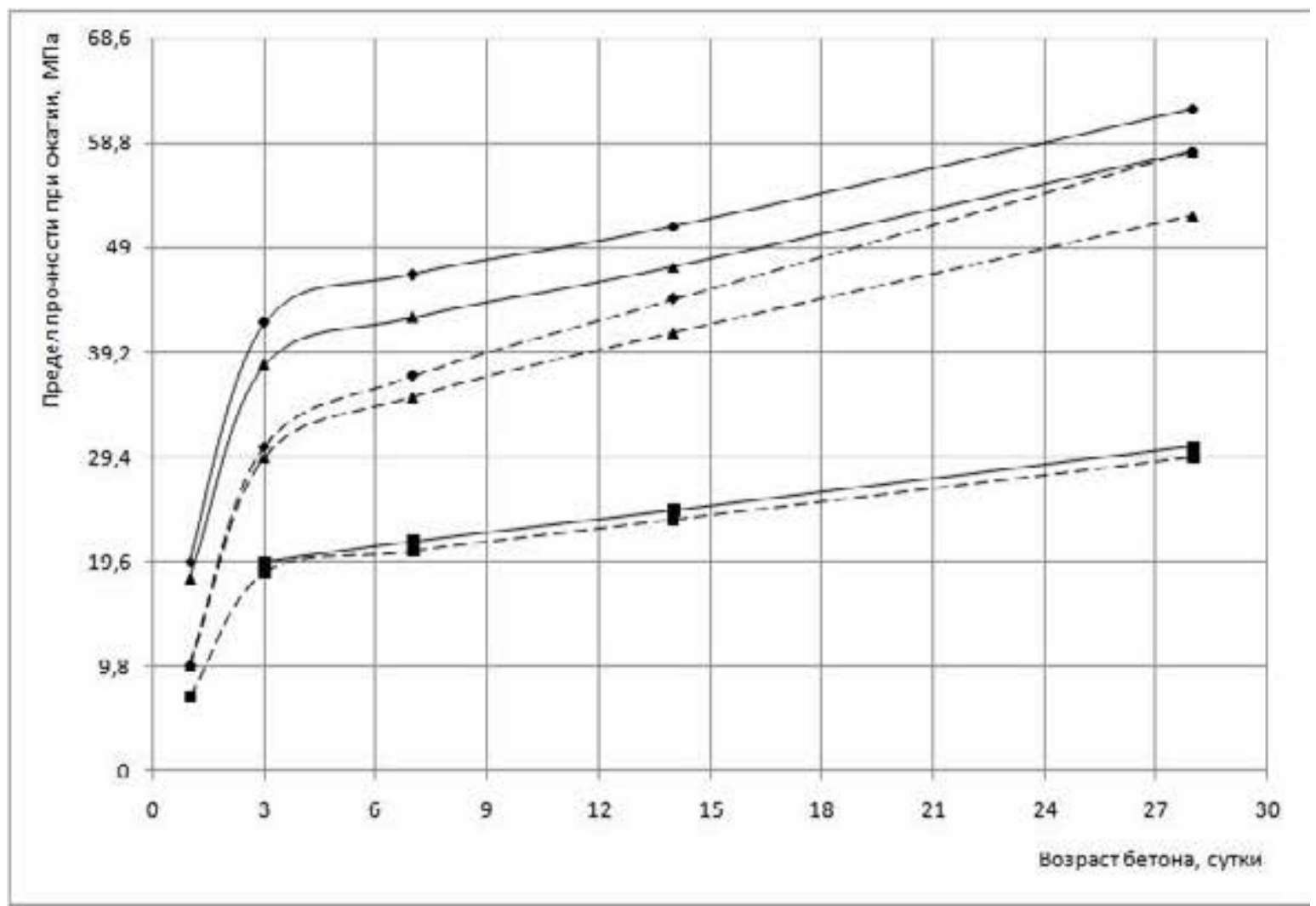

Рис. 2 - Влияние барды на прочность бетонов: $\boldsymbol{\text { 口 }} \mathrm{R} \sigma=200, \boldsymbol{\Delta}$ Rб = 400, $\downarrow$ Rб = 500; (пунктирная линия - бетоны без добавки, сплошная - бетоны с добавкой барды) 
Прочность бетонов определяли в различные сроки твердения на образцах, хранившихся в естественных условиях и пропаренных при температуре $80^{\circ} \mathrm{C}$.

Для получения сравнительных данных о влиянии последрожжевой барды на жесткость (укладываемость, формуемость) бетонной смеси и прочность бетона испытывали бетоны марок 200, 400 и 500 на цементе активностью 49,0 МПа.

Добавки последрожжевой барды наиболее эффективны для бетона с отношением В/Ц, равным 0,3. Для бетонов с низким значением В/Ц при оптимальной добавке последрожжевой барды адсорбционное торможение гидратации цемента практически не влияет на прочность бетона. Как видно из таблицы 1 , продление срока затвердевания высокопрочного бетона с добавкой последрожжевой барды способствует нарастанию его прочности в естественных условиях и при термовлажностной обработке.

Таблица 1.

Влияние времени затвердевания бетона в естественных условиях

\begin{tabular}{|c|c|c|c|c|c|c|c|c|}
\hline \multirow{2}{*}{$\begin{array}{l}\text { Добавка } \\
\text { барды,\% }\end{array}$} & \multirow{2}{*}{ В/Ц } & \multirow{2}{*}{$\begin{array}{c}\text { Укладывае- } \\
\text { мость, с }\end{array}$} & \multicolumn{6}{|c|}{$\begin{array}{c}\text { Прочность при сжатии (в МПа) и затвердевании в } \\
\text { течение }\end{array}$} \\
\hline & & & 1 сут. & 3 сут. & 7 сут. & 28сут. & 3 мес. & 6 мес. \\
\hline- & 0,30 & 30 & 35,1 & 59,6 & 67,8 & 78,5 & 79,2 & 85,3 \\
\hline $0,1-0,15$ & 0,30 & 15 & 39,0 & 69,3 & 73,2 & 88,7 & 90,6 & 98,3 \\
\hline
\end{tabular}

\section{Выводы}

На основании полученных данных можно сделать вывод, что добавка 0,1 - 0,15\% последрожжевой барды почти в 2 раза увеличила подвижность бетонной смеси и на 10 - 15\% увеличила прочность бетона.

\section{Перечень ссылок}

1. А.с. СССР № 485377. Сытник Н.И., Андрианова Г.С. Бетонная смесь; опубл. в Бюл. - № 33. -1975 .

2. Технологія спирту/ В.О. Маринченко, В.А. Домарецький, П.Л. Шиян, В.М. Швець, П.С. Циганков, І.Д. Жолнер./Під ред. проф.. В.О. Мариченка. - Вінниця: “Поділля-2000”, 2003. $496 \mathrm{c}$.

3. Долінський А.А. Використання механізмів і методів ДIВЕ для керування кінетикою перебігу нанорівневих процесів/ А.А. Долінський, А.О. Авраменко, Г.К. Іваницький // Вісник НАН України. - 2013. - №8. - С. 47 - 57. 